\title{
Atividade antagônica in vitro de isolados de Trichoderma spp. ao fungo Phytophthora citrophthora
}

\section{Antagonistic in vitro activity of Trichoderma spp. isolates to the fungi Phytophthora citrophthora}

\author{
Katiane Santiago Silva ${ }^{1 *}$; Tiyoko Nair Hojo Rebouças ${ }^{2}$; Marinês Pereira Bomfim³; \\ Daniela Santiago Silva ${ }^{3}$; Abel Rebouças São José2 ${ }^{2}$ Cleiton Gredson Sabin Benett ${ }^{1}$
}

\section{Resumo}

A citricultura nacional apresenta inúmeras pragas e doenças que limitam sua produção dentre as principais doenças fúngicas da cultura dos citros pode se destacar a gomose. A gomose causada por Phytophthora sp. geralmente se manifesta no colo da planta, provocando podridão e exsudação de goma, podendo expandir-se ocasionando a morte da planta por estrangulamento devido ao ataque do cambio ou floema, o que interrompe o fluxo descendente de seiva. Este trabalho foi realizado com o objetivo de se avaliar a atividade antagônica in vitro, de isolados de Trichoderma spp. ao fungo Phytophthora citrophthora. O fator em estudo foi um patógeno (Phytophthora citrophthora) em cinco ambientes de antagonismo (sem antagonista e com os isolados de Trichoderma viride, T. virens, $T$. harzianu e T. stromaticum). O ensaio in vitro foi realizado por meio do método de cultura pareada. $\mathrm{O}$ delineamento experimental utilizado foi inteiramente casualizado, com 5 tratamentos e 3 repetições, e cada parcela foi representada por três placas de Petri. Os isolados de Trichoderma demonstraram efeito significativo na inibição do crescimento micelial do fungo Phytophthora citrophthora, sendo que o fungo Trichoderma stromaticum apresentou maior antagonismo ao fungo $P$. citrophthora enquanto que o T. harzianum apresentou menor antagonismo.

Palavras-chave: Gomose, doenças fúngicas, citros, controle biológico

\begin{abstract}
Gummosis is among the main fungal diseases of the citrus. It is caused by Phytophthora sp. and usually shows up in the lap of the plant, provoking rottenness and gum exudation, and expands causing the plant death for constrictions in the cambium or phloem which interrupts the descending flow of sap. The objective of this work was to evaluate the antagonistic in vitro activity of Trichoderma spp. to the fungi Phytophthora citrophthora. Phytophthora citrophthora was exposed to five environments of antagonism (without antagonist and with four strains of Trichoderma viride, T. virens, T. harzianu and T. stromaticum). The in vitro essay was accomplished through the method of paired cultures. A completely randomized desing was used with five treatments and three replications, and each plot was represented by three petri dishes. The isolates of Trichoderma demonstrated significant effect in the inhibition of the mycelial growth of the fungi Phytophthora citrophthora, and the fungi Trichoderma stromaticum presented larger antagonism to the fungi P. citrophthora while the T. harzianum presented antagonism smaller.
\end{abstract}

Key words: Gummosis, fungal diseases, citrus, biological control

1 Eng. Agr., Doutorandos em Sistema de Produção. Programa de Pós-graduação em Agronomia - UNESP. Ilha Solteira - SP Brasil. E-mail: kasantiago@ig.com.br.

2 Eng. Agr. Prof. Dr. Departamento de Fitotecnia e Zootecnia - UESB. Vitória da Conquista - BA - Brasil.

3 Biofábrica de Microrganismos - UESB. Vitória da Conquista - BA - Brasil.

* Autor para correspondência 
O Brasil é o maior produtor mundial de citros, tanto para o consumo "in natura" como na forma industrializada em sucos concentrados. Entretanto, como exportador, o Brasil encontra-se em décimo lugar sendo que a Espanha é o maior exportador quando comparada aos outros países produtores. A região Nordeste é a segunda maior produtora de citros no Brasil, ficando atrás apenas da região Sudeste, onde está localizado o Estado de São Paulo, que é historicamente o maior produtor nacional.

A citricultura nacional apresenta inúmeras pragas e doenças que limitam sua produção e comprometem a biossegurança alimentar, dentre as principais doenças fúngicas da cultura pode-se destacar a gomose causada por Phytophthora sp.

As doenças induzidas por Phytophthora, principalmente podridão do colo e da raiz, são as mais sérias doenças de solo do citrus (FEICHTENBERGER, 2001).

A gomose geralmente se manifesta no colo da planta, provocando podridão e exsudação de goma, podendo expandir-se para as raízes, principalmente até 20 ou $30 \mathrm{~cm}$ abaixo do solo e para cima do tronco. Quando todo o diâmetro do tronco é atingido a planta morre por estrangulamento devido ao ataque do cambio ou floema, o que interrompe o fluxo descendente de seiva.

Considerando os custos financeiros e ambientais dos produtos químicos utilizados para controle de Phytophthora, e como as crescentes restrições à presença de resíduos no solo, o uso do controle biológico é considerado uma alternativa importante e tecnicamente justificável.

O uso do controle biológico em substituição ao químico é dependente da disponibilidade e da efetividade dos agentes de controle, bem como dos produtos comerciais contendo estes microorganismos. Entretanto, até o momento, são poucos os produtos biológicos disponíveis no mercado para essa modalidade de controle. Além disso, a maioria não é devidamente registrada para uso em escala comercial (LOPES, 2001).
Trichoderma spp. são importantes fungos saprófitas de solo, e várias espécies são antagônicas a outros fungos e bactérias, incluindo fitopatógenos, principalmente aqueles com estruturas de resistência consideradas difíceis de serem atacadas por microrganismos (MELO, 1996) e fungicidas benzimidazóis (ZAMBOLIN; VALE; SILVA, 1998). Os mecanismos de ação pelos quais o Trichoderma pode atuar são: antibiose, hiperparasitismo, competição e também em alguns casos através de promoção de crescimento (MELO, 1996).

O método da cultura pareada em disco de ágar é o mais largamente utilizado em estudos de antagonismo in vitro, existindo inúmeros relatos de sucesso na seleção de microrganismos, visando ao controle biológico de fitopatógenos (MARIANO, 1993). É um método que permite mensurar o crescimento micelial, bem como os tipos de interação, como hiperparasitismo, formação de clamidosporos, dentre outros (FARIA; CASSETARI NETO; ALBUQUERQUE, 2002).

Os testes in vitro possuem as vantagens de possibilitar a análise de grande número de potenciais antagonistas, permitir o estudo do mecanismo de ação e facilitar a observação das interações antagonistas-patógenos, ao nível ultraestrutural, com auxílio de microscopia ótica ou eletrônica. Além disso, os organismos selecionados in vitro podem servir como fonte de genes para transformação de microrganismos não antagônicos (MARIANO, 1993).

Este trabalho teve o objetivo de avaliar a atividade antagônica in vitro, de isolados de Trichoderma spp. ao fungo Phytophthora citrophthora.

O estudo foi realizado na Biofábrica de Microrganismos da Universidade Estadual do Sudoeste da Bahia, campus de Vitória da Conquista - Bahia. O fator em estudo foi um patógeno (Phytophthora citrophthora) em cinco ambientes de antagonismo (sem antagonista e com os isolados de Trichoderma viride, T. virens, T. harzianum e T. stromaticum, os quais foram obtidos da criação 
estoque (banco fúngico da própria entidade). O isolado de Phytophthora utilizado foi proveniente de amostras de caule coletadas em plantas de Limão cravo infectadas com o fungo Phytophthora citrophthora de um pomar comercial da propriedade agrícola Agropecuária Arizona, situada no município de Anagé - BA.

Para o isolamento as amostras foram lavadas com sabão em água corrente e desinfetadas com álcool a $70 \%$ por 30 segundos e hipoclorito de sódio a $1,5 \%$ por 4 minutos, lavadas em água destilada esterilizada e postas para secar em papel filtro esterilizado. A seguir foram colocadas em câmara úmida para o desenvolvimento das estruturas do patógeno, que após foram repicados em meio de cultura V8, para instalação dos bioensaios de controle.

Para o ensaio in vitro foi empregado o método de cultura pareada em disco de ágar. Cada placa de Petri de $9 \mathrm{~cm}$, contendo o meio de cultura, recebeu dois discos de micélio de $5 \mathrm{~mm}$ de diâmetro, em lados opostos da placa, sendo um do patógeno e outro do isolado de Trichoderma (T. viride, $T$. virens, T. harzianum, T. stromaticum) a ser avaliado. Como testemunha, usou-se o patógeno cultivado isoladamente, colocando-se um disco de micélio no centro de cada placa. As placas foram mantidas em sala climatizada a $23 \pm 3^{\circ} \mathrm{C}$ e fotoperíodo de 12 horas. As avaliações iniciaram após sete dias de incubação, determinando-se o diâmetro das colônias dos patógenos, por meio de uma régua milimetrada medindo-se comprimento e largura das lesões. Para o cálculo da porcentagem de inibição do crescimento micelial, segundo MENTEN et al. (1976), foi aplicada a fórmula: \% inibição $=[$ (crtest - crtrat) /crtest] x 100, onde: crtest $=$ crescimento radial testemunha; crtrat $=$ crescimento radial tratamento.

O delineamento experimental utilizado foi inteiramente casualizado, com 5 tratamentos e 3 repetições, sendo que, cada parcela foi representada por três placas de Petri.

Constatou-se que o pareamento de Phytophthora citrophthora com os isolados de Trichoderma demonstrou efeito significativo no crescimento micelial do fungo.

Os isolados de T.stromaticum, $T$. viride $e$ T. virens apresentaram maior antagonismo ao patógeno estudado, sendo que, o antagonismo por hiperparasitismo foi mais pronunciado quando se utilizou o isolado de $T$. stromaticum, o qual ocupou mais de $52 \%$ da colônia do patógeno, como apresentado na Tabela 1.

O isolado de T. harzianum foi o que apresentou menor antagonismo, com percentagem de inibição de $15,18 \%$ e média de crescimento micelial de $7,49 \mathrm{~cm}$, sem diferir do tratamento controle $(P$. citrophthora) (Tabela 1).

Tabela 1. Crescimento e percentagem de inibição do crescimento micelial de Phytophthora citrophthora em cultivo pareado com isolados de Trichoderma spp. in vitro. Vitória da Conquista-BA, 2006.

\begin{tabular}{lcc}
\hline \multicolumn{1}{c}{ Patógenos } & Crescimento micelial $(\mathrm{cm})$ & \% inibição \\
\hline P. citrophthora X T. stromaticum & $4,22 \mathrm{a}$ & 52,21 \\
P. citrophthora X T. viride & $5,05 \mathrm{a}$ & 42,81 \\
P. citrophthora X T. virens & $6,15 \mathrm{ab}$ & 30,35 \\
P.citrophthora X T. harzianum & $7,49 \mathrm{bc}$ & 15,18 \\
P. citrophthora & $8,83 \mathrm{c}$ & 0,00 \\
\hline
\end{tabular}

Médias seguidas pela mesma letra na coluna, não diferem estatisticamente, pelo teste de Tukey, a $5 \%$ de probabilidade. 
O antagonismo de Trichoderma spp. é explicado pela produção de antibióticos, de amplo espectro, tais como gliotoxina, viridina, trichodermina, suzucacilina, alameticina e dermadina, que têm a capacidade de inibir o desenvolvimento de outros fungos (DENNIS; WEBSTER, 1971). Além de antibióticos, esse microrganismo produz enzimas, como celulase e hemicelulase, as quais degradam materiais lignocelulolíticos e causam lise na parede de células de fungos patogênicos (MELO, 1996).

Pela curva e equação de regressão (Figura 1), vizualiza-se modelos lineares crescentes para o crescimento do patógeno em função do tempo para todos os tratamentos, com diferenças estatísticas entre os tratamentos em relação à testemunha.

May e Kimati (1999) (apud FARIA; CASSETARI NETO; ALBUQUERQUE, 2002) também observaram diferenças entre isolados de Trichoderma quanto a capacidade para hiperparasitar Phytophthora spp. e utilizaram essas informações na seleção de isolados de Trichoderma, com potencial antagônico à $P$. parasitica e consideraram os melhores aqueles que inibiram o crescimento em mais de $66 \%$ da colônia do patógeno.

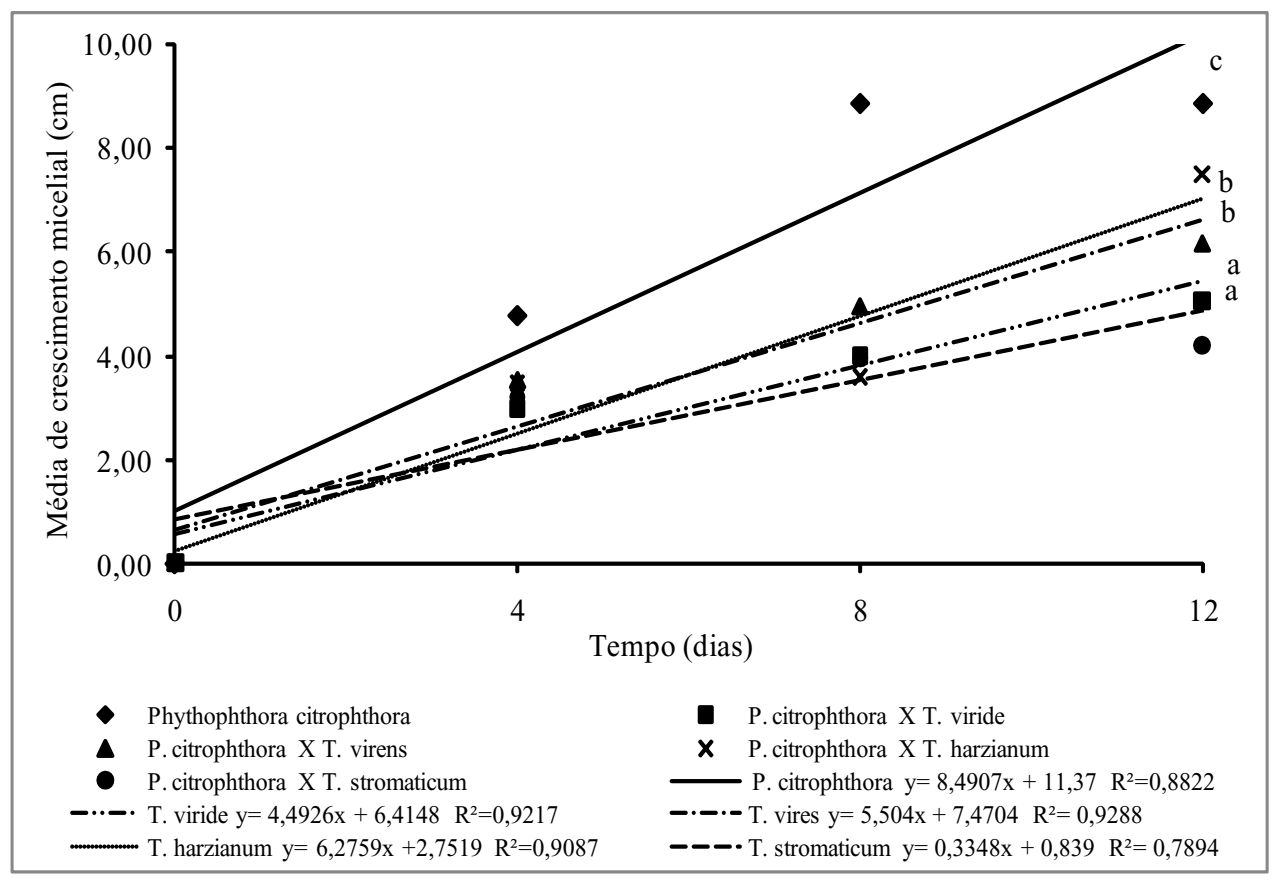

Figura 1. Curva e equação de regressão de cultivo pareado de Phythophthora citrophthora com isolados de Trichoderma spp. e o tempo de incubação. Vitória da Conquista - BA, 2006.

Nas condições em que o estudo foi realizado pode-se concluir que isolados de Trichoderma são capazes de inibir o crescimento micelial do fungo Phytophthora citrophthora, sendo que Trichoderma stromaticum apresenta maior antagonismo ao fungo $P$. citrophthora enquanto que o T. harzianum apresenta menor antagonismo.

\section{Agradecimentos}

À Biofábrica de Microrganismo da Universidade Estadual do Sudoeste da Bahia pela disponibilização de materiais e estrutura utilizados. 


\section{Referências}

DENNIS, C.; WEBSTER, J. Antagonistic properties of species groups of Trichoderma III. Hyphal interactions. Transactions of the British Mycological Society, Cambridge, v. 57, p. 59-363. 1971.

FARIA, A. Y. K.; CASSETARI NETO, D.; ALBUQUERQUE, M. C. A. Atividade antagônica in vitro de Trichoderma harzianum a patógenos de sementes de algodoeiro. Revista Agricultura Tropical, Cuiabá, v. 6, n. 1, p. 59-68, 2002.

FEICHTENBERGER, E. Doenças incitadas por Phytophthora em citros. In: LUZ, E. D. M.; SANTOS, A. F.; MATSUOKA, K.; BEZERRA, J. L. (Eds.). Doenças causadas por Phytophthora no Brasil. Campinas: Livraria Rural, 2001. p. 283-342.

LOPES, E. A. G. L. Controle biológico de Botrytis cinera in vitro em mudas de Eucalyptus sp. 2001.Dissertação (Mestrado em Fitopatologia) - Universidade Federal de Lavras, Lavras-MG.
MARIANO, R. L. R. Métodos de seleção "in vitro" para controle microbiológico. Revisão Anual de Patologia de Plantas, Passo Fundo, v. 1, p. 369-409, 1993.

MELO, I. S. Trichoderma e Gliocladium como bioprotetores de plantas. Revisão Anual de Patologia de Plantas, Passo Fundo, v. 4, p. 261-295, 1996.

MENTEN, J. O. M.; MINUSSI, C. C.; CASTRO, C.; KIMATI, H. Efeito de alguns fungicidas no crescimento micelial de Macrophomina phaseolina (Tass.) Goid. "in vitro". Fitopatologia Brasileira, Brasília, v. 1, n. 2, p. 5766, 1976.

ZAMBOLIN, L.; VALE, F. X. R.; SILVA, M. B. Curso de proteção de plantas: controle de doenças de plantas, principais fungicidas sistêmicos. Brasília: ABEAS, 1998. 
